\title{
Omega 3 Fatty Acid and Skin Diseases
}

\author{
Yu Sawada ${ }^{*}$ Natsuko Saito-Sasaki and Motonobu Nakamura \\ Department of Dermatology, University of Occupational and Environmental Health, Kitakyushu, Japan
}

Humans are exposed to various external environmental factors. Food intake is one of the most influential factors impacting daily lifestyle. Among nutrients obtained from foods, omega-3 polyunsaturated fatty acids (PUFAs) have various beneficial effects on inflammatory diseases. Furthermore, omega-3 PUFA metabolites, including resolvins, are known to demonstrate strong anti-inflammatory effects during allergic and inflammatory diseases; however, little is known regarding the actual impact of these metabolites on skin diseases. In this review, we focused on metabolites that have strong anti-inflammatory actions in various inflammatory diseases, as well as those that present antitumor actions in malignancies, in addition to the actual effect of omega-3 PUFA metabolites on various cells.

\section{OPEN ACCESS}

Edited by:

Laurence Macia

The University of Sydney, Australia

Reviewed by:

Hu Wang,

Johns Hopkins University,

United States

Ivan Milos Stankovic,

University of Belgrade, Serbia

*Correspondence:

Yu Sawada

long-ago@med.uoeh-u.ac.jp

Specialty section:

This article was submitted to

Nutritional Immunology,

a section of the journal

Frontiers in Immunology

Received: 29 October 2020

Accepted: 22 December 2020

Published: 05 February 2021

Citation:

Sawada Y, Saito-Sasaki N and Nakamura M (2021) Omega 3 Fatty Acid and Skin Diseases.

Front. Immunol. 11:623052. doi: 10.3389/fimmu.2020.623052
Keywords: $\omega 3$ polyunsaturated fatty acids, resolvin, protectin, maresin, metabolites

\section{INTRODUCTION}

The environment is fundamental for humans to live on earth and influences various physiological and pathological functions in the human body $(1,2)$. Food intake is an essential task for animals to drive their body and allows us to reconstruct body structure from nutrients (3). Among nutrients derived from foods, fatty acids are a component of cells and are known to control various cellular functions $(4,5)$. Omega-3 polyunsaturated fatty acids (PUFAs) are composed of 18 or more carbon chains, with a double bond three atoms away from the terminal methyl group, and are mainly classified into three representative lipids: $\alpha$-linoleic acid (ALA), docosahexaenoic acids (DHA), and eicosapentaenoic acid (EPA). ALA is enzymatically converted to EPA and subsequently converted into DHA (6). These conversions primarily occur in the liver and are extremely limited owing to the enzyme concentration in the human body (7-9). Therefore, it is reasonable to derive DHA and EPA directly from foods and/or dietary supplements enriched in fish oils.

Omega-3 PUFAs have been known to demonstrate anti-inflammatory actions in various inflammatory diseases, including psoriasis, inflammatory bowel disease, asthma, and rheumatoid arthritis (10-12). In recent studies, omega-3 PUFA metabolites, such as resolvins (Rvs) and maresins, have revealed potent anti-inflammatory actions. Protectins (PD) and D-series Rvs are converted from DHA by 15-lipoxygenase, whereas E-series Rvs are produced from EPA by the cytochrome $\mathrm{P} 450$ pathways or acetylated cyclooxygenase-2. These metabolites have strong antiinflammatory actions in various inflammatory diseases, such as animal models of asthma (13) and colitis (14), as well as antitumor actions in malignancies; however, little is known regarding their role in skin diseases. This review focused on the therapeutic potential of omega-3 PUFA metabolites for inflammatory skin diseases, as well as antitumor actions against cutaneous tumors. 


\section{ANTI-INFLAMMATORY ACTION ON IMMUNE CELLS AND EPITHELIAL CELLS}

Reportedly, omega-3 PUFA metabolites have demonstrated various actions on immune and epithelial cells. In this section, we first reviewed the influence of omega-3 PUFA metabolites on each cell type, including dendritic cells (DCs)/macrophages, T cells/regulatory T cells (Tregs)/B cells, neutrophils, and epithelial cells, which are known to be present in the skin (Table 1).

\section{DCs/Macrophages}

DCs and macrophages play central roles in the acquired immune system to determine the direction of immune responses. As antigen-presenting cells, they take up antigens via phagocytic mechanisms to present antigens to $\mathrm{T}$ cells, to determine the direction of the immune response.

Phagocytosis is promoted by resolvin E1 (RvE1) (15-20), resolvin D1 (RvD1) (20, 34-37), resolvin D2 (RvD2) (20, 64), resolvin $\mathrm{D} 3(\mathrm{RvD} 3)(67,68)$, resolvin $\mathrm{D} 5(\mathrm{RvD} 5)(70)$, protectin D1 (PD1) (15), and maresin 1 (MaR1) (82). For apoptotic cells, the macrophage phagocytosis is enhanced by RvE1 (15), PD1 (15), and RvD1 (34). Phagocyte-dependent bacterial clearance is enhanced by maresin 1 (MaR1) (82), RvD2 (64), RvD3 (67), and RvD5 (70).

Inflammatory cytokine production is negatively regulated by RvE1 (16, 20, 23), RvD1 (20, 38, 40-42), RvD2 (20, 38), RvD3 (71), and MaR1 (38, 78-80). RvE1, RvD1, and RvD2 suppress chemokine (C-C motif) ligand 4 (CCL4), CCL5, interleukin (IL)6 , IL-8, and tumor necrosis factor (TNF)- $\alpha$ induced by human monocyte-derived macrophages co-cultured with tumor cell debris (20), IL-12 by DCs stimulated with pathogen extract (23), and superoxide production by macrophages stimulated with cigarette smoke (16). In macrophages stimulated with lipopolysaccharide (LPS), RvD1, RvD2, and MaR1 suppress IL$1 \beta$ and IL-6 $(38,78,79)$. In contrast, MaR1 promotes the production of the inhibitory cytokine IL-10 (81).

$\mathrm{DCs} /$ macrophages play central roles in antigen presentation, as well as migration into antigen-presenting sites for $\mathrm{T}$ cells to initiate their active forms. RvD1 suppresses antigen presentation by suppressing major histocompatibility complex (MHC) class II and CD40 expression (39). Additionally, DC migration and infiltration into inflamed tissues are negatively regulated by RvE1 (22, 23) and RvD1 (43). RvE1 suppresses the migration of DCs in the skin and into draining lymph nodes, attenuating the acquired immune response (22), while RvD1 attenuates the increased infiltration of M1 macrophages (43).

Owing to the characteristics of antigen-presenting cells as a control tower in the immune response, the polarization of macrophages determines the direction of inflammatory responses. M1 macrophages are induced by interferon (IFN)- $\gamma$, a microbial component. M1 macrophages produce inflammatory cytokines and induce effector cells in polarized Th1 responses. M1 polarization is reportedly suppressed by RvD1 (44) and RvD2 (44). M2 macrophages are generated during enhanced Th2 reactions,

TABLE 1 | Cell specific action of SPMs.

\begin{tabular}{|c|c|c|c|c|}
\hline & $\mathrm{DC} / \mathrm{M} \varphi$ & T cell/Treg/B cell & Neutrophil & Epithelial cell \\
\hline RvE1 & 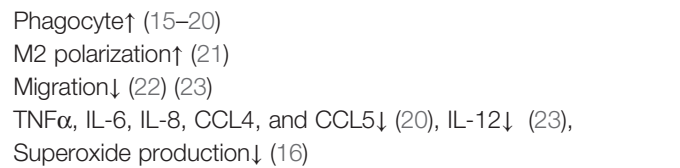 & $\begin{array}{l}\text { Th1/Th17 cells } \\
\text { infiltration } \downarrow \text { (24) } \\
\text { T-cell trafficking } \downarrow(21)\end{array}$ & 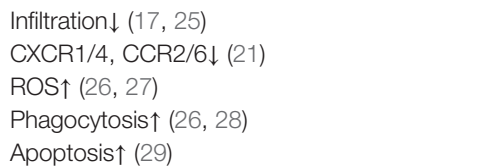 & $\begin{array}{l}\text { Migration } \uparrow(30 \text {, } \\
31)\end{array}$ \\
\hline RvE3 & No report & No report & Migration $\downarrow(32,33)$ & No report \\
\hline RvD1 & 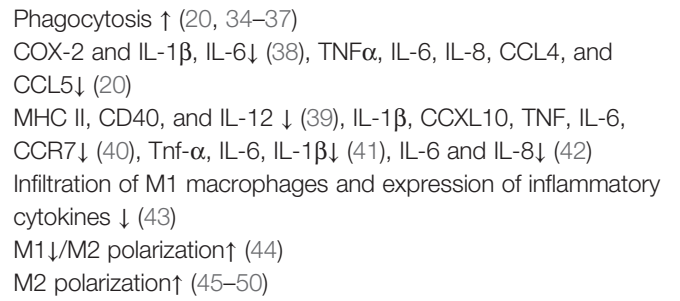 & $\begin{array}{l}\text { TNF- } \alpha, \text { IFN- } \gamma, I L-17 \downarrow \\
\text { (51) } \\
\text { Migration } \downarrow \text { (52) } \\
\text { Treg } \uparrow(34,34,51,53) \\
\text { B cell IgM and IgG } \\
\text { production } \uparrow(54) \\
\text { B-cell IgE production } \downarrow \\
\text { (55) }\end{array}$ & $\begin{array}{l}\text { Apoptosis } \uparrow(50) \\
\text { Infiltration } \downarrow(36,52,56-61) \\
\text { CXCR4 } \downarrow \text { (62) } \\
\text { Phagocytosis } \downarrow \text { (63) }\end{array}$ & $\begin{array}{l}\text { Epithelial barrier } \\
\text { integrity (57) }\end{array}$ \\
\hline RvD2 & 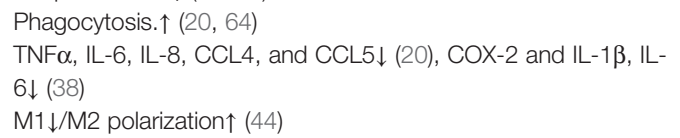 & $\begin{array}{l}\text { TNF- } \alpha, \text { IFN- } \gamma, I L-17 \downarrow \\
(51) \\
\text { Treg } \uparrow(51)\end{array}$ & $\begin{array}{l}\text { Infiltration } \downarrow(64,65) \\
\text { Enhancedneutrophil access to the dermis, but } \\
\text { prevented neutrophil-mediated damage (66) }\end{array}$ & No report \\
\hline RvD3 & Phagocytosis $\uparrow(67,68)$ & & $\begin{array}{l}\text { Migration } \downarrow \text { (68) } \\
\text { Phagocytosis, ROS } \uparrow(67)\end{array}$ & $\begin{array}{l}\text { Proliferation } \uparrow \\
\text { (69) }\end{array}$ \\
\hline RvD5 & Phagocytosis $\uparrow(70)$ & & & \\
\hline PD1 & $\begin{array}{l}\text { Phagocytosis } \uparrow(15) \\
\text { Inflammatory cytokine suppression (71) }\end{array}$ & $\begin{array}{l}\text { Leukocyte infiltration } \downarrow \\
\text { (72). }\end{array}$ & $\begin{array}{l}\text { Infiltration } \downarrow \text { (73-75) } \\
\text { Apoptosis } \uparrow(74)\end{array}$ & $\begin{array}{l}\text { Anti-apoptosis } \\
(76) \\
\text { Anti-apoptosis } \\
(77)\end{array}$ \\
\hline MaR1 & 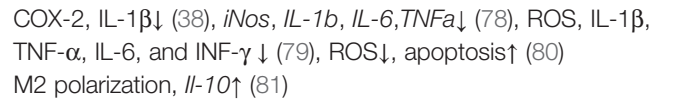 & 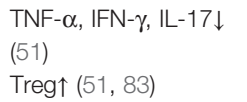 & $\begin{array}{l}\text { Infiltration } \downarrow(84,85) \\
\text { Apoptosis } \uparrow(86)\end{array}$ & $\begin{array}{l}\text { IL-6, IL-8, TNF- } \\
\alpha, \text { CXCL1 } \downarrow(87)\end{array}$ \\
\hline
\end{tabular}


promoting parasite killing (88), tissue repair (89), and immunoregulatory functions (90). M2 polarization is positively regulated by RvD1 (44-50), RvD2 (44), and MaR1 (91).

\section{T Cells/Tregs/B Cells}

$\mathrm{T}$ cells can respond to pathogens by direct contact with the antigen derived from the pathogen and need to migrate to sites in the presence of the antigen. Reportedly, $\mathrm{T}$ cell migration is regulated by $\operatorname{RvE} 1$ (21, 24), RvD1 (52), and PD1 (72). RvE1 decreases the infiltration of Th1 and Th17 cells (24). RvE1 suppresses $\mathrm{T}$ cell infiltration by decreasing the production of RANTES in vascular smooth muscle cells (21).

After the initiation of immune responses by antigenpresenting cells, naïve $\mathrm{T}$ cells develop $\mathrm{T}$ cell responses as an appropriate direction of inflammatory immune responses. RvD1, RvD2, and PD1 suppress inflammatory cytokine production (51). RvD1, RvD2, and PD1 reduce Th1 and Th17 cytokine production (51).

Tregs are promising cells for the maintenance of immune homeostasis and tolerance (92). T cell-mediated autoimmune diseases and allergies are closely related to their deficiency or dysfunction. RvD1, RvD2, and PD1 are known to contribute to the inhibition of immune reactions by increasing Tregs (51).

$B$ cells play an important role in the adaptive immune system. The activation of $\mathrm{B}$ cells is induced following antigen recognition, differentiating to form plasma cells for antibody secretion. RvD1 influences immunoglobulin production by $\mathrm{B}$ cells and increases $\operatorname{IgM}$ and $\operatorname{IgG}$ production (54), as well as reduces $\operatorname{IgE}$ production (55).

\section{Neutrophils}

Neutrophils have various functions, including phagocytosis and antimicrobial peptide production (93). Reportedly, neutrophil phagocytosis is positively regulated by $\operatorname{RvE} 1(26,28), \operatorname{RvD} 1$ (63), and RvD3 (67). In phagocytes, NADPH oxidase is essential for neutrophil microbicidal activity (94). Furthermore, reactive oxygen species (ROS) generation in neutrophils is promoted by RvE1 $(26,27)$ and RvD3 (67). In addition, neutrophil migration is suppressed by $\operatorname{RvE} 1(17,25), \operatorname{RvE} 3(32,33), \operatorname{RvD} 1(36,52,56-$ 61), $\operatorname{RvD} 2(64,65), \operatorname{RvD} 3$ (68), PD1 (73-75), and MaR1 $(84,85)$. RvE1 decreases chemokine receptor expression, including C-C chemokine receptor type 2 (CCR2), CCR6, chemokine (C-X-C motif) receptor 1 (CXCR1), and CXCR4 (21), as well as chemotaxis (26). RvD1 decreases CXCR4 expression (62). Moreover, RvD2 allows neutrophils to enhance their access to the dermis; however, RvD2 demonstrates a protective role against neutrophil-mediated damage (66).

Apoptotic neutrophils progress toward secondary necrosis mediated by the release of caspase 3-processed danger signals (93). Neutrophil apoptosis is reportedly enhanced by RvE1 (29), RvD1 (50), PD1 (74), and MaR1 (86). These metabolites enhance apoptotic cell phagocytosis of macrophages, suppressing secondary necrosis-mediated inflammation.

\section{Epithelial Cells}

Epithelial cells act as the first line of defense against the external environment. As the outermost organ layer, epithelial cells induce inflammatory cytokine and chemokine production to amplify the response to external stimuli. Inflammatory cytokine production is negatively regulated by MaR1 (87). Furthermore, MaR1 suppresses the production of CXCL1, IL6 , IL-8, and TNF- $\alpha$ by bronchial epithelial cells (87).

As the outer organ layer, epithelial cells exhibit migration and proliferation to shield the defect of the first line of defense against external stimuli. RvE1 enhances epithelial cell migration $(30,31)$, RvD3 promotes lung epithelial cell proliferation (69), while RvD1 and PD1 exhibit protective effects toward epithelial cells. Furthermore, RvD1 promotes epithelial barrier integrity (57). PD1 is shown to afford protection against repetitive oxidative stress-induced apoptosis $(76,77)$.

\section{DIFFERENT FUNCTIONS OF PUFA METABOLITES ON IMMUNE CELLS AND EPITHELIAL CELLS}

There are some different effects of PUFA metabolites in immune cells and epithelial cells. RvE1 suppresses immune cell migration $(22,23)$ while it promotes epithelial cell migration $(30,31)$. In addition, PD1 promotes apoptosis of neutrophils (74); however, it enhances anti-apoptosis in epithelial cells $(76,77)$. Although the detailed mechanism remains unclear, a possible other point of action might exist in each different type of cell, because they are located in different body sites and surface layers, which are given the appropriate role in the body.

\section{THE ANTI-INFLAMMATORY ACTION OF PUFA METABOLITES ON SKIN DISEASES}

Several reports have highlighted the anti-inflammatory actions of omega-3 PUFA metabolites on inflammatory skin diseases, including psoriasis, atopic dermatitis, contact hypersensitivity, and ultraviolet (UV) radiation. Furthermore, the antitumor effects of PUFA metabolites on squamous cell carcinoma and melanoma have been reported (Table 2).

TABLE 2 | Anti-inflammatory and anti-tumor action of Omega-3 PUFA metabolites in skin diseases.

\begin{tabular}{ll}
\hline Inflammatory skin disease & Omega-3 PUFA metabolites \\
\hline Psoriasis & $\operatorname{MaR1}(95)$ \\
& $\operatorname{RvE1}(96)$ \\
& $\operatorname{RvD1}(97)$ \\
Atopic dermatitis & $\operatorname{RvE1}(98)$ \\
Contact dermatitis & $\operatorname{RvE1}(22)$ \\
UV radiation & $\operatorname{MaR1}(99)$ \\
Wound healing & $\operatorname{PD1}(48)$ \\
& $\operatorname{RvD1}(100)$ \\
Malignancy & \\
Squamous cell carcinoma & $\operatorname{RvD2}(101)$ \\
Malignant melanoma & $\operatorname{RvD1}(20)$ \\
& $\operatorname{RvD2}(20)$
\end{tabular}




\section{Psoriasis and PUFA Metabolites}

Psoriasis is a representative inflammatory skin disease characterized by scaly erythematous plaques with epidermal hyperplasia (102). Although the underlying mechanism of psoriasis remains unclear, recent studies have revealed some predominant pathways underlying pathological conditions, as well as the contribution of the TNF/IL-23/ IL-17 axis (103). Current biologics targeting IL-17, IL-23, and TNF- $\alpha$ play critical roles in the pathogenesis of psoriasis (104).

Reportedly, MaR1 impairs imiquimod-induced psoriasis-like skin inflammation and IL-23 subcutaneous injection-induced skin inflammation (95). MaR1 decreases lymphocyte and neutrophil infiltration, dermal edema, and epithelial hyperplasia. MaR1 inhibits the production of IL-17A by CD $4^{+}$and $\gamma \delta \mathrm{TCR}^{\text {mid }+}$ cells. Consequently, MaR1 attenuates IL-23 receptor expression on $\mathrm{CD}^{+}$and $\gamma \delta \mathrm{TCR}^{\text {mid+ }}$ cells by inhibiting retinoic acid-related orphan receptor gamma $t$ (ROR $\gamma t$ ) in clathrin-dependent IL-23 receptor internalization.

RvE1 impairs imiquimod-induced psoriatic dermatitis (96). Furthermore, IL-17-producing cells and neutrophils are reduced in the skin following RvE1 treatment. Reportedly, IL-23 and IL-17 are downregulated by RvE1. IL-23 production by DCs, as well as the migration of DCs and IL-17 producing cells, is suppressed by RvE1.

RvD1 reduces acanthosis and hyperkeratosis induced by imiquimod (97). Inflammatory cell infiltration into the dermis is reduced following treatment with RvD1. Consistently, IL-17, IL-23, and TNF- $\alpha$ are decreased by RvD1.

\section{Atopic Dermatitis (AD) and PUFA Metabolites}

$\mathrm{AD}$ is a representative Th2-mediated chronic inflammatory skin disease characterized by inflamed and irritative itchy skin inflammation (105). Several factors are involved in the various environmental factors that drive Th2 dominant skin inflammation, including skin barrier disruption $(106,107)$, pathogens (108), and prostanoids (109). In NC/Nga mice, RvE1 demonstrates antiinflammatory actions in repeated hapten application-induced ADlike skin inflammation (98). RvE1 suppresses IL-4 and IFN- $\gamma$ production by $\mathrm{T}$ cells, as well as serum IgE levels, and reduces the infiltration of eosinophils, mast cells, and T cells in skin lesions.

\section{Contact Dermatitis and PUFA Metabolites}

Contact dermatitis is a common cutaneous allergic reaction that depends on the acquired immune response $(110,111)$. RvE1 impairs the inflammatory response in contact hypersensitivity during the sensitization and elicitation phases (22). During the sensitization phase, RvE1-treated mice exhibit significantly reduced DC migration into draining lymph nodes, subsequently reducing the number of central and effector memory $\mathrm{T}$ cells. Consistently, antigen-specific $\mathrm{T}$ cell proliferation and IFN- $\boldsymbol{\gamma}$ production are reduced by RvE1. In the elicitation phase, RvE1 impairs DC cluster formation, which is essential for the development of elicitation phase inflammation, subsequently suppressing the number of IFN- $\gamma$-producing $\mathrm{CD}^{+} \mathrm{T}$ cells in the skin.

\section{UV Radiation and MaR1}

UV radiation is a representative environment-related skin inflammation that causes acute inflammation characterized by skin inflammation after sun exposure (112). MaR1 suppresses skin swelling as well as macrophage infiltration induced by UVB irradiation (99). Furthermore, MaR1 inhibits UVB irradiationinduced keratinocyte apoptosis, production of inflammatory cytokines, IL-1 $\beta$ and TNF $\alpha$, and oxidative stress.

\section{Wound Healing and PUFA Metabolites}

Damage induced by external factors destroys the skin surface, resulting in skin defects that appear as a wound. As the skin acts as a barrier against the external environment, wounds allow outside pathogens and irritants to infiltrate the body and cause skin inflammation (113). PD1 and RvD1 promote skin wound healing $(48,100)$. In diabetic wounds, RvD1 enhances macrophage phagocytosis, promoting wound closure owing to the reduced number of apoptotic cells (48). Furthermore, PD1 promotes wound closure (100). Skin wounds promote the synthesis of PD1 in the skin; however, in diabetes, the skin suppresses PD1 production. Macrophages are one of the main sources of PD1 in skin wounds and are known to contribute to the development of inflammation and oxidative stress reactions during acute inflammation in diabetic wounds.

\section{Antitumor Effects of PUFA Metabolites}

Squamous cell carcinoma is a keratinocyte-derived malignancy, and the advanced clinical stage of this malignancy remains refractory to current systemic treatments (114). RvD2 suppresses squamous cell carcinoma development (101) and decreases inflammatory chemokines and cytokines, including CXCL10, IL-6, monocyte chemoattractant protein-1 (MCP-1), and TNF- $\alpha$, by cancer cells. In squamous cell carcinoma, $\mathrm{RvD} 2$ decreases the infiltration of neutrophils and suppresses myeloperoxidase (MPO) activity. Additionally, RvD2 enhances the M2 macrophage population and their efferocytosis.

Malignant melanoma is a malignancy derived from melanocytes with severe life-threatening clinical behavior owing to a lack of radical treatment (115). RvD1 and RvD2 suppress melanoma development (20). Furthermore, RvD1 or RvD2 inhibit lung metastasis of melanoma cells and regulate the production of chemokines and cytokines, including CCL4, CCL5, IL-6, IL-8, and TNF- $\alpha$, by human macrophages, providing antitumor immunity.

\section{CLINICAL TRIAL OF OMEGA3 PUFA FOR CUTANEOUS SKIN DISEASES}

Finally, we reviewed the clinical trials of omega 3 PUFAs for cutaneous skin diseases. There are several trials for atopic dermatitis and psoriasis.

The intake of omega-3 supplement improves the Scoring in Atopic Dermatitis (SCORAD) score (116). A double-blind, randomized, placebo-controlled trial showed $\mathrm{AD}$ patients who received daily $\omega 3$ fatty acid supplementation (fish oil, 10\%; $200 \mathrm{~mL}$ ) show high serum EPA concentration and a decreased disease severity of $\mathrm{AD}$ (117).

Psoriasis patients with obesity received energy-restricted foods enriched of $\omega 3$ PUFAs (average $2.6 \mathrm{~g} / \mathrm{d}$ ), and these patients showed impaired Psoriasis Area Score Index (PASI) 
score and Dermatological Life Quality Index (118). A doubleblind, randomized study in multicenter trials showed the group of intaking daily an $\omega 3$ fatty acid (Omegavenous; $200 \mathrm{ml} /$ day with 4.2 gm of both EPA and DHA) decreased total PASI score without serious side effects (119).

Although there have been no clinical trials of cutaneous malignancies, head and neck squamous cell carcinoma has been reported. Supplementation of daily $2 \mathrm{~g}$ EPA intakes impairs the production of serum pro-inflammatory cytokines, reduction of body weight and lean body mass, and increases quality of life in patients with squamous cell carcinoma in head and neck (120).

\section{CONCLUSION}

There are a limited number of research and clinical trials for investigations of the effects of $\omega 3$ PUFA in skin diseases.

\section{REFERENCES}

1. Pamenter ME, Hall JE, Tanabe Y, Simonson TS. Cross-Species Insights Into Genomic Adaptations to Hypoxia. Front Genet (2020) 11:743. doi: 10.3389/ fgene.2020.00743

2. Stellingwerff T, Peeling P, Garvican-Lewis LA, Hall R, Koivisto AE, Heikura IA, et al. Nutrition and Altitude: Strategies to Enhance Adaptation, Improve Performance and Maintain Health: A Narrative Review. Sports Med (2019) 49(Suppl 2):169-84. doi: 10.1007/s40279-019-01159-w

3. Pereira LJ, van der Bilt A. The influence of oral processing, food perception and social aspects on food consumption: a review. J Oral Rehabil (2016) 43 (8):630-48. doi: 10.1111/joor.12395

4. Causeret C, Bentejac M, Bugaut M. Proteins and enzymes of the peroxisomal membrane in mammals. Biol Cell (1993) 77(1):89-104. doi: 10.1016/S0248-4900(05)80178-9

5. Chintalapati S, Kiran MD, Shivaji S. Role of membrane lipid fatty acids in cold adaptation. Cell Mol Biol (Noisy-le-grand) (2004) 50(5):631-42.

6. Burdge G. Alpha-linolenic acid metabolism in men and women: nutritional and biological implications. Curr Opin Clin Nutr Metab Care (2004) 7 (2):137-44. doi: 10.1097/00075197-200403000-00006

7. Burdge GC, Calder PC. Conversion of alpha-linolenic acid to longer-chain polyunsaturated fatty acids in human adults. Reproduct Nutr Dev (2005) 45 (5):581-97. doi: 10.1051/rnd:2005047

8. Burdge GC, Jones AE, Wootton SA. Eicosapentaenoic and docosapentaenoic acids are the principal products of alpha-linolenic acid metabolism in young men*. Br J Nutr (2002) 88(4):355-63. doi: 10.1079/ BJN2002662

9. Burdge GC, Wootton SA. Conversion of alpha-linolenic acid to eicosapentaenoic, docosapentaenoic and docosahexaenoic acids in young women. Br J Nutr (2002) 88(4):411-20. doi: 10.1079/BJN2002689

10. Dyerberg J, Bang HO, Stoffersen E, Moncada S, Vane JR. Eicosapentaenoic acid and prevention of thrombosis and atherosclerosis? Lancet (1978) 2 (8081):117-9. doi: 10.1016/S0140-6736(78)91505-2

11. Horrobin DF. Low prevalences of coronary heart disease (CHD), psoriasis, asthma and rheumatoid arthritis in Eskimos: are they caused by high dietary intake of eicosapentaenoic acid (EPA), a genetic variation of essential fatty acid (EFA) metabolism or a combination of both? Med Hypotheses (1987) 22 (4):421-8. doi: 10.1016/0306-9877(87)90037-5

12. Siscovick DS, Barringer TA, Fretts AM, Wu JH, Lichtenstein AH, Costello RB, et al. Omega-3 Polyunsaturated Fatty Acid (Fish Oil) Supplementation and the Prevention of Clinical Cardiovascular Disease: A Science Advisory From the American Heart Association. Circulation (2017) 135(15):e867-84. doi: 10.1161/CIR.0000000000000482

13. Siddiquee A, Patel M, Rajalingam S, Narke D, Kurade M, Ponnoth DS. Effect of omega-3 fatty acid supplementation on resolvin (RvE1)-mediated
According to previous studies assessing immune cells, various beneficial effects are expected in skin diseases. Furthermore, there are few reports available on keratinocytes, which are a major component of cells present in the epidermis. The detailed action of keratinocytes in the skin needs to be clarified in future research. Because the incidences of inflammatory skin diseases and malignancies are currently increasing, future basic research and clinical trials for $\omega 3$ PUFAs in dermatology fields are expected give us a beneficial information for the daily clinical treatment for skin diseases.

\section{AUTHOR CONTRIBUTIONS}

YS and MN wrote this manuscript, and NS-S conducted a critical review of this paper. All authors contributed to the article and approved the submitted version.

suppression of inflammation in a mouse model of asthma. Immunopharmacol Immunotoxicol (2019) 41(2):250-7. doi: 10.1080/ 08923973.2019.1584903

14. Ishida T, Yoshida M, Arita M, Nishitani Y, Nishiumi S, Masuda A, et al. Resolvin E1, an endogenous lipid mediator derived from eicosapentaenoic acid, prevents dextran sulfate sodium-induced colitis. Inflamm bowel Dis (2010) 16(1):87-95. doi: 10.1002/ibd.21029

15. Schwab JM, Chiang N, Arita M, Serhan CN. Resolvin E1 and protectin D1 activate inflammation-resolution programmes. Nature (2007) 447 (7146):869-74. doi: 10.1038/nature05877

16. Takamiya R, Fukunaga K, Arita M, Miyata J, Seki H, Minematsu N, et al. Resolvin E1 maintains macrophage function under cigarette smoke-induced oxidative stress. FEBS Open Bio (2012) 2:328-33. doi: 10.1016/ j.fob.2012.10.001

17. Oh SF, Pillai PS, Recchiuti A, Yang R, Serhan CN. Pro-resolving actions and stereoselective biosynthesis of $18 \mathrm{~S}$ E-series resolvins in human leukocytes and murine inflammation. J Clin Invest (2011) 121(2):569-81. doi: 10.1172/ JCI42545

18. Ohira T, Arita M, Omori K, Recchiuti A, Van Dyke TE, Serhan CN. Resolvin E1 receptor activation signals phosphorylation and phagocytosis. $J$ Biol Chem (2010) 285(5):3451-61. doi: 10.1074/jbc.M109.044131

19. Hong S, Porter TF, Lu Y, Oh SF, Pillai PS, Serhan CN. Resolvin E1 metabolome in local inactivation during inflammation-resolution. J Immunol (2008) 180(5):3512-9. doi: 10.4049/jimmunol.180.5.3512

20. Sulciner ML, Serhan CN, Gilligan MM, Mudge DK, Chang J, Gartung A, et al. Resolvins suppress tumor growth and enhance cancer therapy. J Exp Med (2018) 215(1):115-40. doi: 10.1084/jem.20170681

21. Liu G, Gong Y, Zhang R, Piao L, Li X, Liu Q, et al. Resolvin E1 attenuates injury-induced vascular neointimal formation by inhibition of inflammatory responses and vascular smooth muscle cell migration. FASEB J (2018) 32 (10):5413-25. doi: 10.1096/fj.201800173R

22. Sawada Y, Honda T, Hanakawa S, Nakamizo S, Murata T, UeharaguchiTanada Y, et al. Resolvin E1 inhibits dendritic cell migration in the skin and attenuates contact hypersensitivity responses. J Exp Med (2015) 212 (11):1921-30. doi: 10.1084/jem.20150381

23. Arita M, Bianchini F, Aliberti J, Sher A, Chiang N, Hong S, et al. Stereochemical assignment, antiinflammatory properties, and receptor for the omega-3 lipid mediator resolvin E1. J Exp Med (2005) 201(5):713-22. doi: 10.1084/jem.20042031

24. Wang H, Zhao Q, Luo D, Yin Y, Li T, Zhao M. Resolvin E1 Inhibits Corneal Allograft Rejection in High-Risk Corneal Transplantation. Invest Ophthalmol Vis Sci (2018) 59(10):3911-9. doi: 10.1167/iovs.18-24562

25. Zhang J, Wang M, Ye J, Liu J, Xu Y, Wang Z, et al. The Anti-inflammatory Mediator Resolvin E1 Protects Mice Against Lipopolysaccharide-Induced Heart Injury. Front Pharmacol (2020) 11:203. doi: 10.3389/fphar.2020.00203 
26. Haas-Stapleton EJ, Lu Y, Hong S, Arita M, Favoreto S, Nigam S, et al. Candida albicans modulates host defense by biosynthesizing the proresolving mediator resolvin E1. PLoS One (2007) 2(12):e1316. doi: 10.1371/journal.pone.0001316

27. Unno Y, Sato Y, Fukuda H, Ishimura K, Ikeda H, Watanabe M, et al. Resolvin E1, but not resolvins E2 and E3, promotes fMLF-induced ROS generation in human neutrophils. FEBS Lett (2018) 592(16):2706-15. doi: 10.1002/1873-3468.13215

28. Herrera BS, Hasturk H, Kantarci A, Freire MO, Nguyen O, Kansal S, et al. Impact of resolvin $\mathrm{E} 1$ on murine neutrophil phagocytosis in type 2 diabetes. Infect Immun (2015) 83(2):792-801. doi: 10.1128/IAI.02444-14

29. El Kebir D, Gjorstrup P, Filep JG. Resolvin E1 promotes phagocytosisinduced neutrophil apoptosis and accelerates resolution of pulmonary inflammation. Proc Natl Acad Sci U S A (2012) 109(37):14983-8. doi: 10.1073/pnas.1206641109

30. Zhang F, Yang H, Pan Z, Wang Z, Wolosin JM, Gjorstrup P, et al. Dependence of resolvin-induced increases in corneal epithelial cell migration on EGF receptor transactivation. Invest Ophthalmol Vis Sci (2010) 51(11):5601-9. doi: 10.1167/iovs.09-4468

31. Quiros M, Feier D, Birkl D, Agarwal R, Zhou DW, García AJ, et al. Resolvin E1 is a pro-repair molecule that promotes intestinal epithelial wound healing. Proc Natl Acad Sci U S A (2020) 117(17):9477-82. doi: 10.1073/ pnas. 1921335117

32. Isobe $\mathrm{Y}$, Arita $\mathrm{M}$, Iwamoto $\mathrm{R}$, Urabe $\mathrm{D}$, Todoroki $\mathrm{H}$, Masuda $\mathrm{K}$, et al. Stereochemical assignment and anti-inflammatory properties of the omega3 lipid mediator resolvin E3. J Biochem (2013) 153(4):355-60. doi: 10.1093/ $\mathrm{jb} / \mathrm{mvs} 151$

33. Isobe $\mathrm{Y}$, Arita $\mathrm{M}$, Matsueda $\mathrm{S}$, Iwamoto R, Fujihara T, Nakanishi $\mathrm{H}$, et al. Identification and structure determination of novel anti-inflammatory mediator resolvin E3, 17,18-dihydroxyeicosapentaenoic acid. J Biol Chem (2012) 287(13):10525-34. doi: 10.1074/jbc.M112.340612

34. Luo B, Han F, Xu K, Wang J, Liu Z, Shen Z, et al. Resolvin D1 Programs Inflammation Resolution by Increasing TGF- $\beta$ Expression Induced by Dying Cell Clearance in Experimental Autoimmune Neuritis. J Neurosci (2016) 36(37):9590-603. doi: 10.1523/JNEUROSCI.0020-16.2016

35. Markworth JF, Brown LA, Lim E, Floyd C, Larouche J, Castor-Macias JA, et al. Resolvin D1 supports skeletal myofiber regeneration via actions on myeloid and muscle stem cells. JCI Insight (2020) 5(18):e137713. doi: 10.1172 /jci.insight. 137713

36. Abdulnour RE, Sham HP, Douda DN, Colas RA, Dalli J, Bai Y, et al. Aspirintriggered resolvin D1 is produced during self-resolving gram-negative bacterial pneumonia and regulates host immune responses for the resolution of lung inflammation. Mucosal Immunol (2016) 9(5):1278-87. doi: $10.1038 / \mathrm{mi} .2015 .129$

37. Dalli J, Colas RA, Serhan CN. Novel n-3 immunoresolvents: structures and actions. Sci Rep (2013) 3:1940. doi: 10.1038/srep01940

38. Caron JP, Gandy JC, Brown JL, Sordillo LM. Docosahexaenoic acid-derived oxidized lipid metabolites modulate the inflammatory response of lipolysaccharide-stimulated macrophages. Prostagland Other Lipid Mediat (2018) 136:76-83. doi: 10.1016/j.prostaglandins.2018.05.006

39. Hua J, Jin Y, Chen Y, Inomata T, Lee H, Chauhan SK, et al. The resolvin D1 analogue controls maturation of dendritic cells and suppresses alloimmunity in corneal transplantation. Invest Ophthalmol Vis Sci (2014) 55(9):5944-51. doi: 10.1167 /iovs.14-14356

40. Sun AR, Wu X, Liu B, Chen Y, Armitage CW, Kollipara A, et al. Proresolving lipid mediator ameliorates obesity induced osteoarthritis by regulating synovial macrophage polarisation. Sci Rep (2019) 9(1):426. doi: 10.1038/s41598-018-36909-9

41. Kain V, Halade GV. Immune responsive resolvin D1 programs peritoneal macrophages and cardiac fibroblast phenotypes in diversified metabolic microenvironment. J Cell Physiol (2019) 234(4):3910-20. doi: 10.1002/jcp.27165

42. Cox R Jr., Phillips O, Fukumoto J, Fukumoto I, Tamarapu Parthasarathy P, Mandry M, et al. Resolvins Decrease Oxidative Stress Mediated Macrophage and Epithelial Cell Interaction through Decreased Cytokine Secretion. PLoS One (2015) 10(8):e0136755. doi: 10.1371/journal.pone.0136755

43. Wang M, Liu M, Zhang J, Liu J, Ye J, Xu Y, et al. Resolvin D1 protects against sepsis-induced cardiac injury in mice. Biofactors (2020) 46(5):766-76. doi: 10.1002/biof.1668
44. Shan K, Feng N, Cui J, Wang S, Qu H, Fu G, et al. Resolvin D1 and D2 inhibit tumour growth and inflammation via modulating macrophage polarization. J Cell Mol Med (2020) 24(14):8045-56. doi: 10.1111/ jcmm.15436

45. Wang CS, Maruyama CL, Easley JT, Trump BG, Baker OJ. AT-RvD1 Promotes Resolution of Inflammation in NOD/ShiLtJ mice. Sci Rep (2017) 7:45525. doi: 10.1038/srep45525

46. Kang JW, Lee SM. Resolvin D1 protects the liver from ischemia/reperfusion injury by enhancing M2 macrophage polarization and efferocytosis. Biochim Biophys Acta (2016) 1861(9 Pt A):1025-35. doi: 10.1016/j.bbalip.2016.06.002

47. Hsiao HM, Sapinoro RE, Thatcher TH, Croasdell A, Levy EP, Fulton RA, et al. A novel anti-inflammatory and pro-resolving role for resolvin D1 in acute cigarette smoke-induced lung inflammation. PLoS One (2013) 8(3): e58258. doi: 10.1371/journal.pone.0058258

48. Tang Y, Zhang MJ, Hellmann J, Kosuri M, Bhatnagar A, Spite M. Proresolution therapy for the treatment of delayed healing of diabetic wounds. Diabetes (2013) 62(2):618-27. doi: 10.2337/db12-0684

49. Rogerio AP, Haworth O, Croze R, Oh SF, Uddin M, Carlo T, et al. Resolvin D1 and aspirin-triggered resolvin D1 promote resolution of allergic airways responses. J Immunol (2012) 189(4):1983-91. doi: 10.4049/jimmunol. 1101665

50. Krishnamoorthy S, Recchiuti A, Chiang N, Yacoubian S, Lee CH, Yang R, et al. Resolvin D1 binds human phagocytes with evidence for proresolving receptors. Proc Natl Acad Sci U S A (2010) 107(4):1660-5. doi: 10.1073/ pnas. 0907342107

51. Chiurchiù V, Leuti A, Dalli J, Jacobsson A, Battistini L, Maccarrone M, et al. Proresolving lipid mediators resolvin D1, resolvin D2, and maresin 1 are critical in modulating $\mathrm{T}$ cell responses. Sci Transl Med (2016) 8 (353):353ra111. doi: 10.1126/scitranslmed.aaf7483

52. Shi J, Zhang X, Jiang L, Zhang L, Dong Y, Midgley AC, et al. Regulation of the inflammatory response by vascular grafts modified with AspirinTriggered Resolvin D1 promotes blood vessel regeneration. Acta Biomater (2019) 97:360-73. doi: 10.1016/j.actbio.2019.07.037

53. Luan H, Wang C, Sun J, Zhao L, Li L, Zhou B, et al. Resolvin D1 Protects Against Ischemia/Reperfusion-Induced Acute Kidney Injury by Increasing Treg Percentages via the ALX/FPR2 Pathway. Front Physiol (2020) 11:285. doi: $10.3389 /$ fphys.2020.00285

54. Ramon S, Gao F, Serhan CN, Phipps RP. Specialized proresolving mediators enhance human B cell differentiation to antibody-secreting cells. J Immunol (2012) 189(2):1036-42. doi: 10.4049/jimmunol.1103483

55. Kim N, Ramon S, Thatcher TH, Woeller CF, Sime PJ, Phipps RP. Specialized proresolving mediators (SPMs) inhibit human B-cell IgE production. Eur $J$ Immunol (2016) 46(1):81-91. doi: 10.1002/eji.201545673

56. Murakami T, Suzuki K, Tamura H, Nagaoka I. Suppressive action of resolvin $\mathrm{D} 1$ on the production and release of septic mediators in D-galactosaminesensitized endotoxin shock mice. Exp Ther Med (2011) 2(1):57-61. doi: $10.3892 /$ etm. 2010.170

57. Krishnamoorthy S, Recchiuti A, Chiang N, Fredman G, Serhan CN. Resolvin D1 receptor stereoselectivity and regulation of inflammation and proresolving microRNAs. Am J Pathol (2012) 180(5):2018-27. doi: 10.1016/j.ajpath.2012.01.028

58. Chen J, Shetty S, Zhang P, Gao R, Hu Y, Wang S, et al. Aspirin-triggered resolvin D1 down-regulates inflammatory responses and protects against endotoxin-induced acute kidney injury. Toxicol Appl Pharmacol (2014) 277 (2):118-23. doi: 10.1016/j.taap.2014.03.017

59. Kim KH, Park TS, Kim YS, Lee JS, Oh YM, Lee SD, et al. Resolvin D1 prevents smoking-induced emphysema and promotes lung tissue regeneration. Int J Chron Obstruct Pulmon Dis (2016) 11:1119-28. doi: $10.2147 / C O P D . S 100198$

60. Xia H, Wang J, Sun S, Wang F, Yang Y, Chen L, et al. Resolvin D1 Alleviates Ventilator-Induced Lung Injury in Mice by Activating PPAR $\gamma / \mathrm{NF}-\mathrm{KB}$ Signaling Pathway. BioMed Res Int (2019) 2019:6254587. doi: 10.1155/ 2019/6254587

61. Zhang HW, Wang Q, Mei HX, Zheng SX, Ali AM, Wu QX, et al. RvD1 ameliorates LPS-induced acute lung injury via the suppression of neutrophil infiltration by reducing CXCL2 expression and release from resident alveolar macrophages. Int Immunopharmacol (2019) 76:105877. doi: 10.1016/ j.intimp.2019.105877 
62. Yaxin W, Shanglong Y, Huaqing S, Hong L, Shiying Y, Xiangdong C, et al. Resolvin D1 attenuates lipopolysaccharide induced acute lung injury through CXCL-12/CXCR4 pathway. J Surg Res (2014) 188(1):213-21. doi: 10.1016/j.jss.2013.11.1107

63. Sekheri M, El Kebir D, Edner N, Filep JG. 15-Epi-LXA(4) and 17-epi-RvD1 restore TLR9-mediated impaired neutrophil phagocytosis and accelerate resolution of lung inflammation. Proc Natl Acad Sci U S A (2020) 117 (14):7971-80. doi: 10.1073/pnas.1920193117

64. Spite M, Norling LV, Summers L, Yang R, Cooper D, Petasis NA, et al. Resolvin D2 is a potent regulator of leukocytes and controls microbial sepsis. Nature (2009) 461(7268):1287-91. doi: 10.1038/nature08541

65. Mizraji G, Heyman O, Van Dyke TE, Wilensky A. Resolvin D2 Restrains Th1 Immunity and Prevents Alveolar Bone Loss in Murine Periodontitis. Front Immunol (2018) 9:785. doi: 10.3389/fimmu.2018.00785

66. Bohr S, Patel SJ, Sarin D, Irimia D, Yarmush ML, Berthiaume F. Resolvin D2 prevents secondary thrombosis and necrosis in a mouse burn wound model. Wound Repair Regen (2013) 21(1):35-43. doi: 10.1111/j.1524-475X.2012. 00853.x

67. Norris PC, Arnardottir H, Sanger JM, Fichtner D, Keyes GS, Serhan CN. Resolvin D3 multi-level proresolving actions are host protective during infection. Prostagland Leukot Essent Fatty Acids (2018) 138:81-9. doi: 10.1016/j.plefa.2016.01.001

68. Dalli J, Winkler JW, Colas RA, Arnardottir H, Cheng CY, Chiang N, et al. Resolvin D3 and aspirin-triggered resolvin D3 are potent immunoresolvents. Chem Biol (2013) 20(2):188-201. doi: 10.1016/j.chembiol.2012.11.010

69. Colby JK, Abdulnour RE, Sham HP, Dalli J, Colas RA, Winkler JW, et al. Resolvin D3 and Aspirin-Triggered Resolvin D3 Are Protective for Injured Epithelia. Am J Pathol (2016) 186(7):1801-13. doi: 10.1016/j.ajpath.2016. 03.011

70. Werz O, Gerstmeier J, Libreros S, De la Rosa X, Werner M, Norris PC, et al. Human macrophages differentially produce specific resolvin or leukotriene signals that depend on bacterial pathogenicity. Nat Commun (2018) 9(1):59. doi: 10.1038/s41467-017-02538-5

71. Merched AJ, Ko K, Gotlinger KH, Serhan CN, Chan L. Atherosclerosis: evidence for impairment of resolution of vascular inflammation governed by specific lipid mediators. FASEB J (2008) 22(10):3595-606. doi: 10.1096/fj.08112201

72. Ariel A, Li PL, Wang W, Tang WX, Fredman G, Hong S, et al. The docosatriene protectin D1 is produced by $\mathrm{TH} 2$ skewing and promotes human T cell apoptosis via lipid raft clustering. J Biol Chem (2005) 280 (52):43079-86. doi: 10.1074/jbc.M509796200

73. Masterson JC, McNamee EN, Fillon SA, Hosford L, Harris R, Fernando SD, et al. Eosinophil-mediated signalling attenuates inflammatory responses in experimental colitis. Gut (2015) 64(8):1236-47. doi: 10.1136/gutjnl-2014306998

74. Li X, Li C, Liang W, Bi Y, Chen M, Dong S. Protectin D1 promotes resolution of inflammation in a murine model of lipopolysaccharideinduced acute lung injury via enhancing neutrophil apoptosis. Chin Med J (Engl) (2014) 127(5):810-4.

75. Serhan CN, Gotlinger K, Hong S, Lu Y, Siegelman J, Baer T, et al. Antiinflammatory actions of neuroprotectin D1/protectin D1 and its natural stereoisomers: assignments of dihydroxy-containing docosatrienes. J Immunol (2006) 176(3):1848-59. doi: 10.4049/jimmunol.176.3.1848

76. Faghiri Z, Bazan NG. PI3K/Akt and mTOR/p70S6K pathways mediate neuroprotectin D1-induced retinal pigment epithelial cell survival during oxidative stress-induced apoptosis. Exp Eye Res (2010) 90(6):718-25. doi: 10.1016/j.exer.2010.03.002

77. Mukherjee PK, Marcheselli VL, Barreiro S, Hu J, Bok D, Bazan NG. Neurotrophins enhance retinal pigment epithelial cell survival through neuroprotectin D1 signaling. Proc Natl Acad Sci U S A (2007) 104 (32):13152-7. doi: 10.1073/pnas.0705949104

78. Huang R, Vi L, Zong X, Baht GS. Maresin 1 resolves aged-associated macrophage inflammation to improve bone regeneration. FASEB J (2020) 34(10):13521-32. doi: 10.1096/fj.202001145R

79. Marcon R, Bento AF, Dutra RC, Bicca MA, Leite DF, Calixto JB. Maresin 1, a proresolving lipid mediator derived from omega- 3 polyunsaturated fatty acids, exerts protective actions in murine models of colitis. J Immunol (2013) 191(8):4288-98. doi: 10.4049/jimmunol.1202743
80. Zhang P, Yin Y, Wang T, Li W, Li C, Zeng X, et al. Maresin 1 mitigates concanavalin A-induced acute liver injury in mice by inhibiting ROSmediated activation of NF- $\mathrm{KB}$ signaling. Free Radic Biol Med (2020) 147:23-36. doi: 10.1016/j.freeradbiomed.2019.11.033

81. Martínez-Fernández L, González-Muniesa P, Laiglesia LM, Sáinz N, PrietoHontoria PL, Escoté X, et al. Maresin 1 improves insulin sensitivity and attenuates adipose tissue inflammation in ob/ob and diet-induced obese mice. FASEB J (2017) 31(5):2135-45. doi: 10.1096/fj.201600859R

82. Chiang N, Libreros S, Norris PC, de la Rosa X, Serhan CN. Maresin 1 activates LGR6 receptor promoting phagocyte immunoresolvent functions. J Clin Invest (2019) 129(12):5294-311. doi: 10.1172/JCI129448

83. Jin S, Chen H, Li Y, Zhong H, Sun W, Wang J, et al. Maresin 1 improves the Treg/Th17 imbalance in rheumatoid arthritis through miR-21. Ann Rheum Dis (2018) 77(11):1644-52. doi: 10.1136/annrheumdis-2018-213511

84. Gong J, Wu ZY, Qi H, Chen L, Li HB, Li B, et al. Maresin 1 mitigates LPSinduced acute lung injury in mice. Br J Pharmacol (2014) 171(14):3539-50. doi: 10.1111/bph.12714

85. Tang Q, Che C, Lin J, He H, Zhao W, Lv L, et al. Maresin1 regulates neutrophil recruitment and IL-10 expression in Aspergillus fumigatus keratitis. Int Immunopharmacol (2019) 69:103-8. doi: 10.1016/ j.intimp.2019.01.032

86. Gong J, Liu H, Wu J, Qi H, Wu ZY, Shu HQ, et al. MARESIN 1 PREVENTS LIPOPOLYSACCHARIDE-INDUCED NEUTROPHIL SURVIVAL AND ACCELERATES RESOLUTION OF ACUTE LUNG INJURY. Shock (2015) 44(4):371-80. doi: 10.1097/SHK.0000000000000434

87. Nordgren TM, Heires AJ, Wyatt TA, Poole JA, LeVan TD, Cerutis DR, et al. Maresin-1 reduces the pro-inflammatory response of bronchial epithelial cells to organic dust. Respir Res (2013) 14(1):51. doi: 10.1186/ 1465-9921-14-51

88. Noël W, Raes G, Hassanzadeh Ghassabeh G, De Baetselier P, Beschin A. Alternatively activated macrophages during parasite infections. Trends Parasitol (2004) 20(3):126-33. doi: 10.1016/j.pt.2004.01.004

89. Wynn TA. Fibrotic disease and the $\mathrm{T}(\mathrm{H}) 1 / \mathrm{T}(\mathrm{H}) 2$ paradigm. Nat Rev Immunol (2004) 4(8):583-94. doi: 10.1038/nri1412

90. Mantovani A, Sica A, Sozzani S, Allavena P, Vecchi A, Locati M. The chemokine system in diverse forms of macrophage activation and polarization. Trends Immunol (2004) 25(12):677-86. doi: 10.1016/ j.it.2004.09.015

91. Akagi D, Chen M, Toy R, Chatterjee A, Conte MS. Systemic delivery of proresolving lipid mediators resolvin D2 and maresin 1 attenuates intimal hyperplasia in mice. FASEB J (2015) 29(6):2504-13. doi: 10.1096/fj.14265363

92. Wing JB, Sakaguchi S. Foxp $3^{+} \mathrm{T}(\mathrm{reg})$ cells in humoral immunity. Int Immunol (2014) 26(2):61-9. doi: 10.1093/intimm/dxt060

93. Nauseef WM, Borregaard N. Neutrophils at work. Nat Immunol (2014) 15 (7):602-11. doi: 10.1038/ni.2921

94. El-Benna J, Dang PM, Gougerot-Pocidalo MA, Elbim C. Phagocyte NADPH oxidase: a multicomponent enzyme essential for host defenses. Arch Immunol Ther Exp (Warsz) (2005) 53(3):199-206.

95. Saito-Sasaki N, Sawada Y, Mashima E, Yamaguchi T, Ohmori S, Yoshioka H, et al. Maresin-1 suppresses imiquimod-induced skin inflammation by regulating IL-23 receptor expression. Sci Rep (2018) 8(1):5522. doi: 10.1038/s41598-018-23623-9

96. Sawada Y, Honda T, Nakamizo S, Otsuka A, Ogawa N, Kobayashi Y, et al. Resolvin E1 attenuates murine psoriatic dermatitis. Sci Rep (2018) 8 (1):11873. doi: 10.1038/s41598-018-30373-1

97. Xu J, Duan X, Hu F, Poorun D, Liu X, Wang X, et al. Resolvin D1 attenuates imiquimod-induced mice psoriasiform dermatitis through MAPKs and NFKB pathways. J Dermatol Sci (2018) 89(2):127-35. doi: 10.1016/ j.jdermsci.2017.10.016

98. Kim TH, Kim GD, Jin YH, Park YS, Park CS. Omega-3 fatty acid-derived mediator, Resolvin E1, ameliorates 2,4-dinitrofluorobenzene-induced atopic dermatitis in NC/Nga mice. Int Immunopharmacol (2012) 14(4):384-91. doi: 10.1016/j.intimp.2012.08.005

99. Cezar TLC, Martinez RM, Rocha CD, Melo CPB, Vale DL, Borghi SM, et al. Treatment with maresin 1, a docosahexaenoic acid-derived pro-resolution lipid, protects skin from inflammation and oxidative stress caused by UVB irradiation. Sci Rep (2019) 9(1):3062. doi: 10.1038/s41598-019-39584-6 
100. Hong S, Tian H, Lu Y, Laborde JM, Muhale FA, Wang Q, et al. Neuroprotectin/protectin D1: endogenous biosynthesis and actions on diabetic macrophages in promoting wound healing and innervation impaired by diabetes. Am J Physiol Cell Physiol (2014) 307(11):C1058-67. doi: 10.1152/ajpcell.00270.2014

101. Ye Y, Scheff NN, Bernabé D, Salvo E, Ono K, Liu C, et al. Anti-cancer and analgesic effects of resolvin D2 in oral squamous cell carcinoma. Neuropharmacology (2018) 139:182-93. doi: 10.1016/j.neuropharm.2018.07.016

102. Hawkes JE, Yan BY, Chan TC, Krueger JG. Discovery of the IL-23/IL-17 Signaling Pathway and the Treatment of Psoriasis. J Immunol (2018) 201 (6):1605-13. doi: 10.4049/jimmunol.1800013

103. Hawkes JE, Chan TC, Krueger JG. Psoriasis pathogenesis and the development of novel targeted immune therapies. J Allergy Clin Immunol (2017) 140(3):645-53. doi: 10.1016/j.jaci.2017.07.004

104. Tokuyama M, Mabuchi T. New Treatment Addressing the Pathogenesis of Psoriasis. Int J Mol Sci (2020) 21(20):7488. doi: 10.3390/ijms21207488

105. Weidinger S, Beck LA, Bieber T, Kabashima K, Irvine AD. Atopic dermatitis. Nat Rev Dis Primers (2018) 4(1):1. doi: 10.1038/s41572-018-0001-Z

106. Palmer CN, Irvine AD, Terron-Kwiatkowski A, Zhao Y, Liao H, Lee SP, et al. Common loss-of-function variants of the epidermal barrier protein filaggrin are a major predisposing factor for atopic dermatitis. Nat Genet (2006) 38 (4):441-6. doi: 10.1038/ng1767

107. Kawasaki H, Nagao K, Kubo A, Hata T, Shimizu A, Mizuno H, et al. Altered stratum corneum barrier and enhanced percutaneous immune responses in filaggrin-null mice. J Allergy Clin Immunol (2012) 129(6):1538-46.e6. doi: 10.1016/j.jaci.2012.01.068

108. Nakatsuji T, Chen TH, Two AM, Chun KA, Narala S, Geha RS, et al. Staphylococcus aureus Exploits Epidermal Barrier Defects in Atopic Dermatitis to Trigger Cytokine Expression. J Invest Dermatol (2016) 136 (11):2192-200. doi: 10.1016/j.jid.2016.05.127

109. Sawada Y, Honda T, Nakamizo S, Nakajima S, Nonomura Y, Otsuka A, et al. Prostaglandin E(2) (PGE(2))-EP2 signaling negatively regulates murine atopic dermatitis-like skin inflammation by suppressing thymic stromal lymphopoietin expression. J Allergy Clin Immunol (2019) 144(5):126573.e9. doi: 10.1016/j.jaci.2019.06.036

110. Honda T, Egawa G, Grabbe S, Kabashima K. Update of immune events in the murine contact hypersensitivity model: toward the understanding of allergic contact dermatitis. J Invest Dermatol (2013) 133(2):303-15. doi: 10.1038/ jid.2012.284

111. Natsuaki Y, Egawa G, Nakamizo S, Ono S, Hanakawa S, Okada T, et al. Perivascular leukocyte clusters are essential for efficient activation of effector T cells in the skin. Nat Immunol (2014) 15(11):1064-9. doi: $10.1038 /$ ni.2992
112. Bernard JJ, Gallo RL, Krutmann J. Photoimmunology: how ultraviolet radiation affects the immune system. Nat Rev Immunol (2019) 19(11):688701. doi: 10.1038/s41577-019-0185-9

113. Martin P, Nunan R. Cellular and molecular mechanisms of repair in acute and chronic wound healing. Br J Dermatol (2015) 173(2):370-8. doi: 10.1111/bjd.13954

114. Burton KA, Ashack KA, Khachemoune A. Cutaneous Squamous Cell Carcinoma: A Review of High-Risk and Metastatic Disease. Am J Clin Dermatol (2016) 17(5):491-508. doi: 10.1007/s40257-016-0207-3

115. Jenkins RW, Fisher DE. Treatment of Advanced Melanoma in 2020 and Beyond. J Invest Dermatol (2020) 141(1):23-31. doi: 10.1016/j.jid.2020.03.943

116. Eriksen BB, Kåre DL. Open trial of supplements of omega 3 and 6 fatty acids, vitamins and minerals in atopic dermatitis. J Dermatol Treat (2006) 17 (2):82-5. doi: 10.1080/09546630600621946

117. Mayser P, Mayer K, Mahloudjian M, Benzing S, Krämer HJ, Schill WB, et al. A double-blind, randomized, placebo-controlled trial of n-3 versus n- 6 fatty acid-based lipid infusion in atopic dermatitis. JPEN J Parenteral Enteral Nutr (2002) 26(3):151-8. doi: 10.1177/0148607102026003151

118. Guida B, Napoleone A, Trio R, Nastasi A, Balato N, Laccetti R, et al. Energyrestricted, n-3 polyunsaturated fatty acids-rich diet improves the clinical response to immuno-modulating drugs in obese patients with plaque-type psoriasis: a randomized control clinical trial. Clin Nutr (Edinburgh Scotland) (2014) 33(3):399-405. doi: 10.1016/j.clnu.2013.09.010

119. Elajami TK, Colas RA, Dalli J, Chiang N, Serhan CN, Welty FK. Specialized proresolving lipid mediators in patients with coronary artery disease and their potential for clot remodeling. FASEB J Off Publ Fed Am Societies Exp Biol (2016) 30(8):2792-801. doi: 10.1096/fj.201500155R

120. Solís-Martínez O, Plasa-Carvalho V, Phillips-Sixtos G, Trujillo-Cabrera Y, Hernández-Cuellar A, Queipo-García GE, et al. Effect of Eicosapentaenoic Acid on Body Composition and Inflammation Markers in Patients with Head and Neck Squamous Cell Cancer from a Public Hospital in Mexico. Nutr Cancer (2018) 70(4):663-70. doi: 10.1080/01635581.2018.1460678

Conflict of Interest: The authors declare that the research was conducted in the absence of any commercial or financial relationships that could be construed as a potential conflict of interest.

Copyright (c) 2021 Sawada, Saito-Sasaki and Nakamura. This is an open-access article distributed under the terms of the Creative Commons Attribution License (CC BY). The use, distribution or reproduction in other forums is permitted, provided the original author(s) and the copyright owner(s) are credited and that the original publication in this journal is cited, in accordance with accepted academic practice. No use, distribution or reproduction is permitted which does not comply with these terms. 